\title{
Switching to Pitavastatin in Statin-Treated Low HDL-C Patients Further Improves the Lipid Profile and Attenuates Minute Myocardial Damage
}

\author{
Chikao Ibuki ${ }^{\mathrm{a}, \mathrm{d}}$, Yoshihiko Seino ${ }^{\mathrm{a}}$, Toshiaki Otsuka ${ }^{\mathrm{b}}$, Nakahisa Kimata ${ }^{\mathrm{a}}$, \\ Toru Inami ${ }^{\mathrm{a}}$, Ryo Munakata ${ }^{\mathrm{a}}$, Kyoichi Mizuno ${ }^{\mathrm{c}}$
}

\begin{abstract}
Background: The aim of this study is to determine the prevalence of minute myocardial damage (MMD) in already statin-treated dyslipidemic patients with a low high-density lipoprotein-cholesterol (HDL-C) level, and to evaluate whether pitavastatin could affect the lipid profiles and biomarkers reflecting myocardial stress and injury.
\end{abstract}

Methods: Twenty patients (15 men; age $66 \pm 8)$ being treated with any statin but who had HDL-C $<40 \mathrm{mg} / \mathrm{dL}$, were switched to pitavastatin $(2 \mathrm{mg} /$ day $)$ treatment. The patient lipid profiles and the levels of N-terminal pro-brain natriuretic peptide (NT-proBNP), high-sensitive troponin $\mathrm{T}$ (hsTnT), and high-sensitive C-reactive protein (hs-CRP) were evaluated for six months.

Results: At three months after the statin replacement, the HDLC significantly increased from $37 \pm 3 \mathrm{mg} / \mathrm{dL}$ to $40 \pm 5 \mathrm{mg} / \mathrm{dL}$ (P $<0.05$ ), and the low-density lipoprotein-cholesterol (LDL-C) and LDL-C/HDL-C ratio significantly reduced $(100 \pm 28 \mathrm{mg} / \mathrm{dL}$ to 86 $\pm 22 \mathrm{mg} / \mathrm{dL}, \mathrm{P}<0.05 ; 2.68 \pm 0.67$ to $2.17 \pm 0.64, \mathrm{P}<0.05$, respectively), and these changes were sustained for six months. In the whole study population, no significant changes were observed in the NT-proBNP, hsTnT, or hsCRP for six months. However, in 11 cases who showed a positive $(>0.003 \mathrm{ng} / \mathrm{mL}) \mathrm{hsTnT}$ at baseline, a significant reduction in the hsTnT was observed $(0.016 \pm 0.020$ $\mathrm{ng} / \mathrm{mL}$ to $0.014 \pm 0.020 \mathrm{ng} / \mathrm{mL}, \mathrm{P}<0.05)$, and its percent reduction significantly correlated with the percent increase in HDL-C $(\mathrm{r}=$ $-0.68, \mathrm{P}<0.05)$.

\section{Manuscript accepted for publication September 5, 2012}

${ }^{a}$ Cardiovascular Center, Nippon Medical School Chiba Hokusoh Hospital, Chiba, Japan

${ }^{\mathrm{b}}$ Department of Hygiene and Public Health, Nippon Medical School, Tokyo, Japan

'Division of Cardiology, Nippon Medical School, Tokyo, Japan

${ }^{\mathrm{d}}$ Corresponding author: Chikao Ibuki, Cardiovascular Center, Nippon Medical School Chiba Hokusoh Hospital, Kamagari 1715, Inzai,

Chiba, 270-1694, Japan. Email: ibuki@nms.ac.jp

doi: http://dx.doi.org/10.4021/jocmr1108w
Conclusions: MMD (positive hsTnT) was observed in more than half of patients with low HDL-C despite the administration of any statin, and the replacement of their previous statin with pitavastatin further improved their lipid profiles and led to better myocardial protection, possibly mediated via the elevation of the HDL-C level.

Keywords: Statin; High-density lipoprotein-cholesterol; Minute myocardial damage; Troponin

\section{Introduction}

High-density lipoprotein cholesterol (HDL-C) has an atheroprotective effect in blood vessels [1, 2], and it has been established that a low serum level of HDL-C is a cardiovascular risk factor independent from the low-density lipoprotein cholesterol (LDL-C) level [3]. As clinical trials have consistently shown that the pharmacological intervention using inhibitors of 3-hydroxy-3-methylglutaryl coenzyme A reductase (statins) result in favorable effects on cardiovascular morbidity and mortality in patients with hypercholesterolemia and/or cardiovascular diseases [4-7], lowering the LDL-C has been the mainstay of therapy for dyslipidemic patients. In those trials, however, substantial elevation of the HDL-C level (5-15\%) has also been reported, and raising the HDL-C level may contribute, at least in part, to the benefit of statins. In fact, it has been demonstrated in a meta-analysis that a decrease in LDL-C and an increase in HDL-C are independent predictors of coronary atheroma regression [8].

Statin therapy has been shown to exhibit myocardial protection when it is used for patients undergoing percutaneous coronary intervention [9]. Minute myocardial damage (MMD), that can become detectable with cardiac sensitive and specific biomarkers such as troponins, has been documented in patients with heart failure and stable coronary artery disease, and the serum troponin levels are associated with the disease severity and prognosis $[10,11]$. Moreover, the development of a high sensitive assay of troponin $\mathrm{T}$ has made it possible to detect MMD even in subjects without apparent cardiovascular disease, and the pathogenic contri- 
Table 1. Baseline Patient Characteristics

$\begin{array}{ll}\text { Age, years } & 66.4 \pm 7.8 \\ \text { Gender (\%) } & \text { Male, } 15(75 \%) \text {; Female, } 5(25 \%) \\ \text { Body mass index } & 24.8 \pm 3.4 \\ \text { Current smokers (\%) } & 5(25 \%) \\ \text { Co-morbidity (\%) } & \text { HT } 11(55 \%), \text { DM } 6(30 \%), \text { CAD } 8(40 \%) \\ \text { Statin before the enrollment }(\%) & \text { Pravastatin } 10(50 \%) \text {; Simvastatin } 1(5 \%) ; \\ & \text { Atorvastatin } 8(40 \%) \text {, Rosuvastatin } 1(5 \%) \\ \text { Co-administration }(\%) & \text { CCB, } 13(65 \%) ; \text { ACEI and/or ARB, } 12(60 \%) ; B B, 8(40 \%) ; \\ & \text { Diuretics, } 3(15 \%), \text { Anti-thrombotics, } 10(50 \%)\end{array}$

$\mathrm{HT}$ : hypertension, DM: diabetes mellitus; CAD: coronary artery disease; CCB: calcium channel blocker; ACEl: angiotensin converting enzyme inhibitor; ARB: angiotensin receptor blocker, BB: beta blocker.

bution of coronary risk factors in MMD has been proposed [12]. However, it remains unknown how dyslipidemia, particularly that complicated with a low level of HDL-C, indicates MMD, and whether the MMD observed in such patients can be influenced by statin therapy.

We performed the present study to determine the prevalence of MMD in already statin-treated dyslipidemic patients with a low HDL-C level, and to evaluate whether pitavastatin, which has been shown to most prominently increase the serum HDL-C among the various statins [13], could affect both the lipid profile and biomarkers indicating myocardial stress and injury in these patients.

\section{Materials and Methods}

\section{Study population}

This study was performed from October 2010 to August 2011 at the outpatient clinic of the Cardiovascular Center, Nippon Medical School Chiba Hokusoh Hospital. Dyslipidemic patients with a HDL-C value below $40 \mathrm{mg} / \mathrm{dL}$ despite the prescription of any statin for at least six months, with an age of 20 - 80 years old, were enrolled in this study. The exclusion criteria were acute coronary syndrome or coronary recanalization therapy within six months, impaired renal (serum creatinine $\geq 1.5 \mathrm{mg} / \mathrm{dL}$ ) and/or liver function, heart failure, pregnancy, familial hypercholesterolemia or a terminal systemic condition of any etiology. This study was approved by the Investigation Review Board of the hospital, and all patients gave written informed consent for their participation.

\section{Protocol}

In all patients, the statin was changed to pitavastatin $(2 \mathrm{mg} /$ day). The lipid profile and standard biochemical parameters were measured at baseline, and again at three and six months after initiating the treatment with pitavastatin. The levels of $\mathrm{N}$-terminal pro-brain natriuretic peptide (NT-proBNP), highsensitive troponin $\mathrm{T}$ (hsTnT), and high-sensitive C-reactive ptotein (hsCRP) were assessed at baseline and six months.

\section{Biochemical measurements}

Blood samples were obtained intravenously after overnight fasting. Standard enzymatic methods were adopted for measurement of the serum total cholesterol (TC), triglycerides (TG), and creatinine. The serum HDL-C level was measured using the direct method. The LDL-C level was determined using Friedwald's equation as follows, unless the TG level was below $400 \mathrm{mg} / \mathrm{dL}$ [14]: LDL-C $=\mathrm{TC}-(\mathrm{HDL}-\mathrm{C}+\mathrm{TG} / 5)$.

The serum NT-proBNP and hsTnT were measured using an electrochemiluminescence immunoassay (Roche Diagnostics), and hsCRP was measured by a latex turbidimetric immunoassay (Siemens Healthcare Diagnostics). The lower detection limit of the hsTnT assay was $0.003 \mathrm{ng} / \mathrm{mL}$. Other biochemical parameters were measured with the UV method using an autoanalyzer (Hitachi 7,700DPP). The estimated glomerular filtration rate (eGFR) was calculated according to the following equation presented by the Japanese Society of Nephrology [15]: eGFR $\left(\mathrm{mL} / \mathrm{min} / 1.73 \mathrm{~m}^{2}\right)=194 \times$ serum creatinine $^{-1.094} \times \operatorname{age}^{-0.287}(\times 0.739$, if female $)$.

\section{Statistical analysis}

Numerical values were expressed as the means \pm standard deviation. Serial changes in the lipid profile were assessed with a repeated analysis of variance followed by Dunnet's t-test. Changes in the NT-proBNP, hsTnT, and hsCRP levels were assessed with a Wicoxon t-test. The correlation be- 
Table 2. Serial Changes in the Laboratory Data of the Overall Subjects

\begin{tabular}{llll}
\hline & Baseline & 3 months & 6 months \\
\hline TC (mg/dL) & $176 \pm 29$ & $160 \pm 27^{*}$ & $167 \pm 24$ \\
HDL-C (mg/dL) & $37 \pm 3$ & $40 \pm 5^{*}$ & $41 \pm 6^{*}$ \\
TG (mg/dL) & $192 \pm 80$ & $169 \pm 78$ & $187 \pm 69$ \\
LDL-C (mg/dL) & $100 \pm 28$ & $86 \pm 22^{*}$ & $89 \pm 24^{*}$ \\
L/H ratio & $2.68 \pm 0.67$ & $2.17 \pm 0.64^{* *}$ & $2.18 \pm 0.68^{*}$ \\
Creatinine (mg/dL) & $0.89 \pm 0.20$ & $0.88 \pm 0.21$ & $0.90 \pm 0.22$ \\
AST (IU/L) & $24 \pm 9$ & $26 \pm 9$ & $26 \pm 12$ \\
ALT (IU/L) & $26 \pm 13$ & $27 \pm 11$ & $27 \pm 12$ \\
CPK (IU/L) & $125 \pm 173$ & $102 \pm 54$ & $91 \pm 38$ \\
NT-proBNP (pg/mL) & $181 \pm 272$ & & $257 \pm 440$ \\
hsTnT (ng/mL) & $0.009 \pm 0.011$ & & $0.007 \pm 0.009$ \\
hsCRP (ng/mL) & $2,994 \pm 6,572$ & & $884 \pm 653$ \\
\hline
\end{tabular}

TC: total cholesterol; HDL-C: high density lipoprotein cholesterol; TG: triglycerides; LDL-C: low density lipoprotein cholesterol; L/H: LDL-C/HDL-C; AST: asparatate aminotransferase; ALT: alanine aminotransferase; CPK: creatine phosphokinase; NT-pro BNP: N-terminal pro-brain natriuretic peptide; hsTnT: high sensitive troponin T; hsCRP: high sensitive $C$-reactive protein. *: $\mathrm{P}<0.05$ vs baseline, ${ }^{* *}$ : $\mathrm{P}<0.01$ vs baseline

tween lipid profiles and the hsTnT level was analyzed with Spearman's test. Values of $\mathrm{P}<0.05$ were regarded as being statistically significant.

\section{Results}

The baseline characteristics of the study subjects are shown in Table 1 . The mean age was 66.4 years and $75 \%$ of subjects were male. The most prevalent co-morbidity was hypertension, and more than half patients had been administered antihypertensives such as angiotensin receptor blockers and calcium channel blockers. In $90 \%$ of the patients, the statin being administered before the study enrollment was pravastatin or atorvastatin.

At three months after the replacement of the statin with $2 \mathrm{mg}$ /day pitavastatin, the TC and LDL-C were significantly reduced $(-9.1 \%$ and $-14.0 \%$, respectively), and the HDL-C level was significantly elevated $(+8.1 \%)$, resulting in a significant reduction in the LDL-C/HDL-C $(\mathrm{L} / \mathrm{H})$ ratio (Table 2). These improvements in the lipid profile were sustained for another three months. Neither complications nor abnormal laboratory fluctuations were shown noted in the present study patients after the statin replacement.

In the entire study population, no significant changes were observed in the NT-proBNP, hsTnT, or hsCRP for six months after the commencement of pitavastatin treatment. There were no statistically significant differences in these biomarkers at baseline between $\mathrm{CAD}$ and non-CAD patients $(0.009 \pm 0.011 \mathrm{ng} / \mathrm{mL}$ and $0.011 \pm 0.009 \mathrm{ng} / \mathrm{mL}$, respectively, NS). However, at baseline, $55 \%$ of patients showed a positive ( $>0.003 \mathrm{ng} / \mathrm{mL}$ ) hsTnT value, and a statistically significant reduction in the hsTnT was observed in such patients at the six month evaluation (baseline $0.016 \pm 0.020$ $\mathrm{ng} / \mathrm{mL} ; 6$ months $0.014 \pm 0.020 \mathrm{ng} / \mathrm{mL}, \mathrm{P}<0.05$ ) (Fig. 1), although in the patients without a positive hsTnT value, there was not significant change during this period (baseline 0.003 $\pm 0.001 \mathrm{ng} / \mathrm{mL} ; 6$ months $0.003 \pm 0.001 \mathrm{ng} / \mathrm{mL}$ ). In positive hsTnT patients, the percent change of hsTnT during the six months significantly correlated with the percent change in the HDL-C value $(\mathrm{r}=-0.68, \mathrm{P}<0.05)$ among the various lipid parameters (Fig. 2). There was no significant difference in the hsTnT at baseline between the CAD and non-CAD patients $(0.009 \pm 0.011 \mathrm{ng} / \mathrm{mL}$ and $0.011 \pm 0.009 \mathrm{ng} / \mathrm{mL}$, respectively, NS).

\section{Discussion}

In the present study, the replacement of another statin with 
A

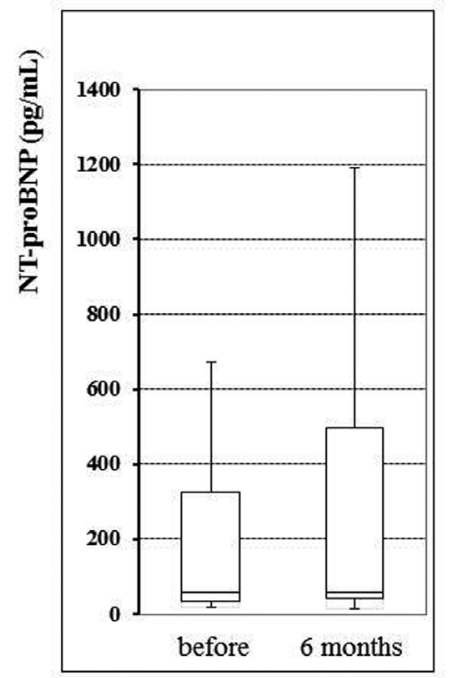

B

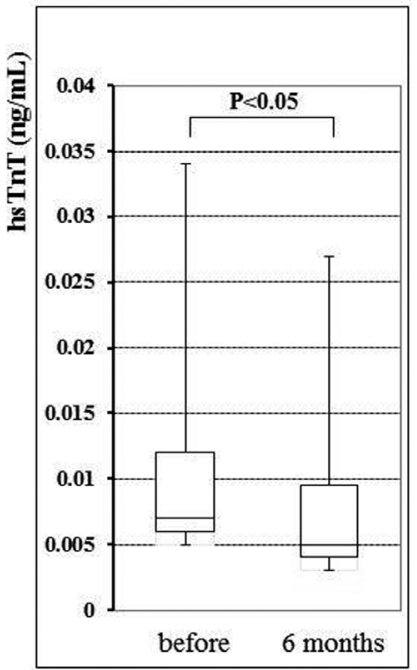

$\mathrm{C}$

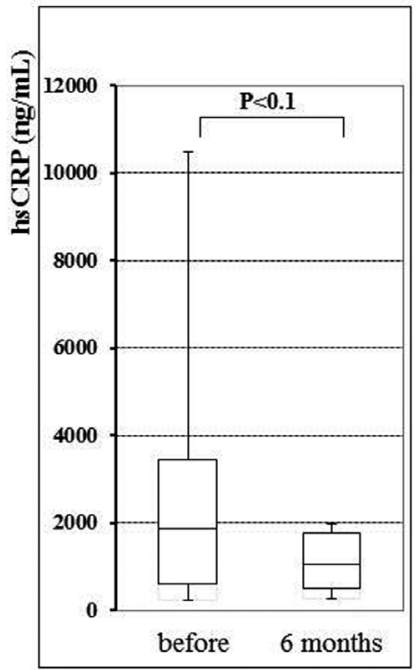

Figure 1. Serum N-terminal pro-brain natriuretic peptide (NT-proBNP) (A), high-sensitive troponin T (hsTnT) (B), and high-sensitve C-reactive protein (hsCRP) (C) levels before and at six months after the replacement of the previous statin with $2 \mathrm{mg} /$ day pitavastatin.

pitavastatin in dyslipidemic patients with a low HDL-C level resulted in a further improvement in the lipid profile for three to six months without deleterious effects. Although patients with acute coronary syndrome or recent coronary recanalization therapy were excluded in this study, more than half of the patients showed a positive $(>0.003 \mathrm{ng} / \mathrm{mL})$ hsTnT value, and in these patients, a significant reduction in the hsTnT level was observed at six months after the statin replacement. Interestingly, such a reduction in the hsTnT significantly correlated with the increase in the HDL-C, but not with changes in other lipid parameters.

\section{Improvement of the lipid profile by pitavastatin}

It has been shown in epidemiological studies that a low level of HDL-C is a potential risk factor for future cardiovascular events, independent of the LDL-C level [16-18], and that an increase in the HDL-C level is associated with a reduced risk of coronary artery disease[19, 20]. Regarding the clinical significance of the elevation of HDL-C induced by a phar-
A

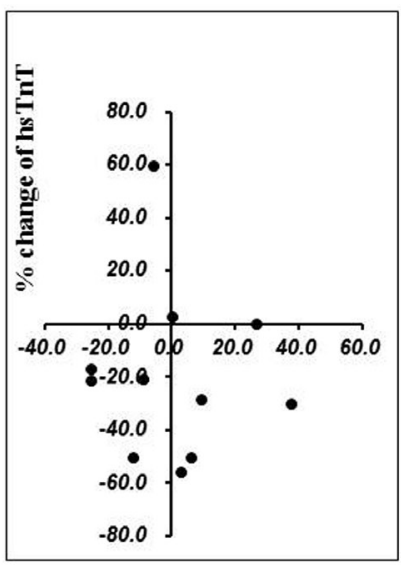

$\%$ change of TC
B

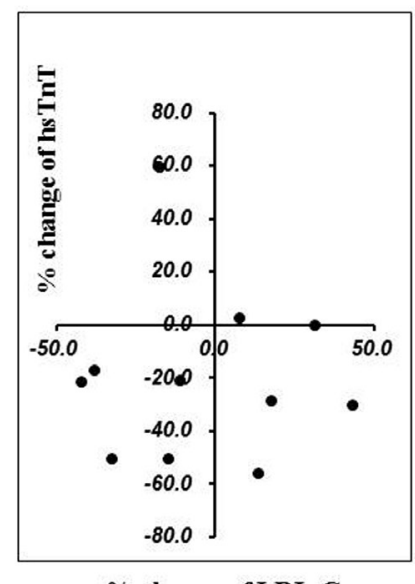

\% change of LDL-C
$\mathrm{C}$

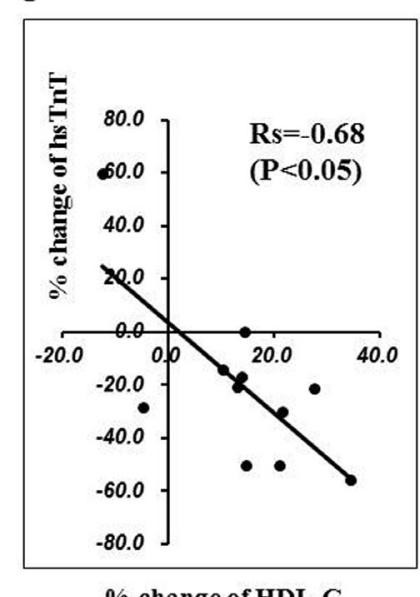

Figure 2. The relationship between the percent change in the high-sensitive troponin $T$ (hsTnT) level (vertical axis) and the percent change in the total cholesterol (TC) (A), low-density lipoprotein cholesterol (LDL-C) (B), and high-density lipoprotein cholesterol (HDL-C) (C) levels (horizontal axis, respectively) for six months after the statin replacement. The percent change in the hsTnT inversely correlated with the change in the HDL-C level (Rs $=-0.68, P<0.05)$. 
macological intervention, Nicholls et al have demonstrated, in a meta-analysis of four controlled trials using intra-vascular ultrasound, that substantial cononary plaque regression was observed in patients who had a LDL-C of less than 87.5 $\mathrm{mg} / \mathrm{dL}$ or a percent increase in the HDL-C of more than $7.5 \%$ after statin treatment [8]. This finding suggests that statininduced elevation of the HDL-C level is associated with antiatherosclerotic effects in the cardiovascular system, although it is still unclear as to whether the atherosclerotic regression, or at least the slowing of progression, can translate to a meaningful improvement in the clinical outcome.

Pitavastatin is characterized as a statin that has a potent action to increase the HDL-C level. The LIVES study [21], a prospective post-marketing surveillance study in which 20,000 Japanese dyslipidemic patients were enrolled, showed an apparent reduction of LDL-C by $31.3 \%$ and an increase of HDL-C by $5.9 \%$ with the administration of 2 $\mathrm{mg}$ of pitavastatin daily. In that study, the favorable effect of pitavastatin on the HDL-C level was more prominent in the low HDL-C subgroup (24.6\% increases in the HDL-C concentration). Although the increase in the HDL-C level by $8.1 \%$ shown in the present study is minor compared to the finding observed in the low HDL-C subgroup of the LIVES study, it should be noted that in our study, pitavastatin was administered to patients who had already been previously treated with other statins, and therefore, not to statin-naive patients.

The mechanism(s) by which statins increase the HDL$\mathrm{C}$ level remains unknown. Possible mechanisms include remodeling of HDL-C particles [22], inhibition of the activity of the cholesterol-ester transfer protein (CETP) [23], and statin-induced promotion of hepatic apolipoprotein A-I production [24]. Pitavastatin has been shown to promote the expression of apolipoprotein A-I and ABCA1 mRNA more efficiently than other statins [25]. Although pitavastatin has been shown to have as potent an anti-atherosclerotic action as atorvastatin in patients with acute coronary syndrome in the JAPAN-ACS study [26], it is unclear whether such beneficial effects are attributable to the increase in the HDL-C level or to the direct action of pitavastatin.

\section{Attenuation of myocardial injury}

Cardiac troponins are sensitive and specific biomarkers of myocardial injury, and are the prerequisite tool for the diagnosis of acute coronary syndrome [27-29]. It has been reported that many patients with heart failure show an elevation of the serum troponin T level, and its elevation is a predictive factor of the disease outcome [30-33], suggesting a profound impact for ongoing minute myocardial damage (MMD) in the pathogenesis of heart failure. With regard to the prevalence of positive troponin $\mathrm{T}$ in stable coronary artery disease patients, Omland et al, using a high sensitive assay for troponin $\mathrm{T}$ which was 10 times more sensitive than the conventional assays, have demonstrated that $97 \%$ of patient show hsTnT values above the detection limit (0.001 $\mathrm{ng} / \mathrm{mL}$ ) [11]. We have previously reported that, in a workbased population free from cardiovascular disease, $80 \%$ of subjects show positive ( $>0.002 \mathrm{ng} / \mathrm{mL}$ ) hsTnT values, and that the levels are associated with the Framingham risk prediction score [12]. The present data showing that more than half of patients have signs of MMD at baseline despite statin therapy is consistent with the previous findings, and suggests that dyslipidemia can result in myocardial injury even in the absence of heart failure or acute coronary syndrome.

Statins are known to alleviate peri-procedural myocardial injury in patients undergoing coronary intervention, partly due to inhibition of coronary microembolism resulting from the plaque rupture [9]. The mechanism underlying the attenuation of MMD observed after the statin replacement with pitavastatin cannot be clarified from the present data. However, this is the first paper that evaluated the effect of pitavastatin on the hsTnT level in dyslipidemic patients already being treated with another statin. The significant correlation between the percent change in the HDL-C level and the reduction of the hsTnT observed in the subpopulation of patients who were hsTnT positive in the present study may mean that HDL-C particles could prevent myocardial injury via coronary plaque stabilization. In this regard, although $40 \%$ of our patients had an apparent history of stable CAD, a substantial number of non-CAD patients may also have suffered from silent or undiagnosed CAD. In fact, we have reported that vulnerable plaques can exist in angiographically non-diseased coronary arteries [34]. Therefore, there is a possibility that the increase in the HDL-C level induced by pitavastatin stabilized coronary silent vulnerable plaques in both CAD and non-CAD patients.

However, it has not been explicitly established that the quantitative change per se in the serum HDL-C level results in anti-atherosclerotic effects. Clinical trials adopting pharmacological inhibitors of CETP have hitherto failed to establish any clinical benefit, despite their substantial elevation of the HDL-C level [35]. It is possible that pitavastatin might have exerted its myocardial protection through mechanisms independent from those related to lipid metabolism. For example, it is possible that the anti-inflammatory action of pitavastatin contributed to the protection in the present study [36], as hsCRP tended to decrease after pitavastatin treatment in the subpopulation showing MMD.

\section{Limitations of the study}

The present study has several limitations. First, this study enrolled a small number of patients with an open and single arm design. However, the present study was a proof-of-concept study performed to investigate the effects of statin replacement with pitavastatin on the lipid profile and MMD for dyslipidemic patients who had a low HDL-C level despite 
treatment with other statins. Whether the elevation of the HDL-C by the statin replacement results in beneficial outcomes warrants a large scale study in the future. Second, the present study included both CAD and non-CAD patients. In general, these 2 types of patients have quite different backgrounds in terms of their future risk of cardiovascular events, and therefore, the achievement target of LDL-C level is low in patients with $\mathrm{CAD}(<100 \mathrm{mg} / \mathrm{dL})$ for the secondary prevention according to the guidelines of the Japanese Atherosclerosis Society [37]. The target HDL-C level is, however, the same $(\geq 40 \mathrm{mg} / \mathrm{dL})$ regardless of the presence of CAD, and the use of strict statin therapy is rational for both types of patients.

\section{Conclusions}

The replacement of other statins with pitavastatin in dyslipidemic patients with a low HDL-C resulted in further improvement in the lipid profile for at least six months. Furthermore, the statin replacement decreased the hsTnT value during this period in patients with a positive hsTnT value at baseline, and its reduction significantly correlated with an increase in the HDL-C. In dyslipidemic patients with a low HDL-C level, pitavastatin should be administered for better management of the lipid profile and possible attenuation of MMD.

\section{Grant Support}

The present investigation was partly supported by the grant of Scientific Research from the Ministry of Education, Culture, Sports, Science and Technology (22590611).

\section{Conflict of Interests}

There are no conflicts of interest with regard to the present study.

\section{References}

1. Plump AS, Scott CJ, Breslow JL. Human apolipoprotein A-I gene expression increases high density lipoprotein and suppresses atherosclerosis in the apolipoprotein E-deficient mouse. Proc Natl Acad Sci U S A. 1994;91(20):9607-9611.

2. Badimon JJ, Badimon L, Fuster V. Regression of atherosclerotic lesions by high density lipoprotein plasma fraction in the cholesterol-fed rabbit. J Clin Invest. 1990;85(4):1234-1241.

3. Stamler J, Wentworth D, Neaton JD. Is relationship between serum cholesterol and risk of premature death from coronary heart disease continuous and graded? Findings in 356,222 primary screenees of the Multiple Risk Factor Intervention Trial (MRFIT). JAMA. 1986;256(20):2823-2828.

4. Randomised trial of cholesterol lowering in 4444 patients with coronary heart disease: the Scandinavian Simvastatin Survival Study (4S). Lancet. 1994;344(8934):13831389.

5. Prevention of cardiovascular events and death with pravastatin in patients with coronary heart disease and a broad range of initial cholesterol levels. The Long-Term Intervention with Pravastatin in Ischaemic Disease (LIPID) Study Group. N Engl J Med. 1998;339(19):13491357.

6. Downs JR, Clearfield M, Weis S, Whitney E, Shapiro DR, Beere PA, Langendorfer A, et al. Primary prevention of acute coronary events with lovastatin in men and women with average cholesterol levels: results of AFCAPS/TexCAPS. Air Force/Texas Coronary Atherosclerosis Prevention Study. JAMA. 1998;279(20):16151622.

7. Sacks FM, Pfeffer MA, Moye LA, Rouleau JL, Rutherford JD, Cole TG, Brown L, et al. The effect of pravastatin on coronary events after myocardial infarction in patients with average cholesterol levels. Cholesterol and Recurrent Events Trial investigators. N Engl J Med. 1996;335(14):1001-1009.

8. Nicholls SJ, Tuzcu EM, Sipahi I, Grasso AW, Schoenhagen $\mathrm{P}, \mathrm{Hu} \mathrm{T}$, Wolski K, et al. Statins, high-density lipoprotein cholesterol, and regression of coronary atherosclerosis. JAMA. 2007;297(5):499-508.

9. Mega S, Patti G, Cannon CP, Di Sciascio G. Preprocedural statin therapy to prevent myocardial damage in percutaneous coronary intervention: a review of randomized trials. Crit Pathw Cardiol. 2010;9(1):19-22.

10. Setsuta K, Seino Y, Ogawa T, Arao M, Miyatake Y, Takano T. Use of cytosolic and myofibril markers in the detection of ongoing myocardial damage in patients with chronic heart failure. Am J Med. 2002;113(9):717722 .

11. Omland T, de Lemos JA, Sabatine MS, Christophi CA, Rice MM, Jablonski KA, Tjora S, et al. A sensitive cardiac troponin $\mathrm{T}$ assay in stable coronary artery disease. N Engl J Med. 2009;361(26):2538-2547.

12. Otsuka T, Kawada T, Ibuki C, Seino Y. Association between high-sensitivity cardiac troponin $\mathrm{T}$ levels and the predicted cardiovascular risk in middle-aged men without overt cardiovascular disease. Am Heart J. 2010;159(6):972-978.

13. Sasaki J, Ikeda Y, Kuribayashi T, Kajiwara K, Biro S, Yamamoto K, Ageta M, et al. A 52-week, randomized, open-label, parallel-group comparison of the tolerability and effects of pitavastatin and atorvastatin on high-density lipoprotein cholesterol levels and glucose metabo- 
lism in Japanese patients with elevated levels of lowdensity lipoprotein cholesterol and glucose intolerance. Clin Ther. 2008;30(6):1089-1101.

14. Friedewald WT, Levy RI, Fredrickson DS. Estimation of the concentration of low-density lipoprotein cholesterol in plasma, without use of the preparative ultracentrifuge. Clin Chem. 1972;18(6):499-502.

15. Matsuo S, Imai E, Horio M, Yasuda Y, Tomita K, Nitta $\mathrm{K}$, Yamagata K, et al. Revised equations for estimated GFR from serum creatinine in Japan. Am J Kidney Dis. 2009;53(6):982-992.

16. Wilson PW, Abbott RD, Castelli WP. High density lipoprotein cholesterol and mortality. The Framingham Heart Study. Arteriosclerosis. 1988;8(6):737-741.

17. Okamura T, Hayakawa T, Kadowaki T, Kita Y, Okayama A, Ueshima $\mathrm{H}$. The inverse relationship between serum high-density lipoprotein cholesterol level and all-cause mortality in a 9.6-year follow-up study in the Japanese general population. Atherosclerosis. 2006;184(1):143150.

18. Barter P, Gotto AM, LaRosa JC, Maroni J, Szarek M, Grundy SM, Kastelein JJ, et al. HDL cholesterol, very low levels of LDL cholesterol, and cardiovascular events. N Engl J Med. 2007;357(13):1301-1310.

19. Gordon T, Castelli WP, Hjortland MC, Kannel WB, Dawber TR. High density lipoprotein as a protective factor against coronary heart disease. The Framingham Study. Am J Med. 1977;62(5):707-714.

20. Rubins HB, Robins SJ, Collins D, Fye CL, Anderson JW, Elam MB, Faas FH, et al. Gemfibrozil for the secondary prevention of coronary heart disease in men with low levels of high-density lipoprotein cholesterol. Veterans Affairs High-Density Lipoprotein Cholesterol Intervention Trial Study Group. N Engl J Med. 1999;341(6):410418.

21. Yokote K, Shimano H, Urashima M, Teramoto T. Efficacy and safety of pitavastatin in Japanese patients with hypercholesterolemia: LIVES study and subanalysis. Expert Rev Cardiovasc Ther. 2011;9(5):555-562.

22. Bays H, Stein EA. Pharmacotherapy for dyslipidaemia-current therapies and future agents. Expert Opin Pharmacother. 2003;4(11):1901-1938.

23. Guerin M, Lassel TS, Le Goff W, Farnier M, Chapman MJ. Action of atorvastatin in combined hyperlipidemia : preferential reduction of cholesteryl ester transfer from HDL to VLDL1 particles. Arterioscler Thromb Vasc Biol. 2000;20(1):189-197.

24. Martin G, Duez H, Blanquart C, Berezowski V, Poulain P, Fruchart JC, Najib-Fruchart J, et al. Statin-induced inhibition of the Rho-signaling pathway activates PPARalpha and induces HDL apoA-I. J Clin Invest. 2001;107(11):1423-1432.

25. Maejima T, Yamazaki H, Aoki T, Tamaki T, Sato F, Kitahara M, Saito Y. Effect of pitavastatin on apolipopro- tein A-I production in HepG2 cell. Biochem Biophys Res Commun. 2004;324(2):835-839.

26. Hiro T, Kimura T, Morimoto T, Miyauchi K, Nakagawa Y, Yamagishi M, Ozaki Y, et al. Effect of intensive statin therapy on regression of coronary atherosclerosis in patients with acute coronary syndrome: a multicenter randomized trial evaluated by volumetric intravascular ultrasound using pitavastatin versus atorvastatin (JAPAN-ACS [Japan assessment of pitavastatin and atorvastatin in acute coronary syndrome] study). J Am Coll Cardiol. 2009;54(4):293-302.

27. Antman EM, Tanasijevic MJ, Thompson B, Schactman $\mathrm{M}, \mathrm{McCabe} \mathrm{CH}$, Cannon CP, Fischer GA, et al. Cardiacspecific troponin I levels to predict the risk of mortality in patients with acute coronary syndromes. N Engl J Med. 1996;335(18):1342-1349.

28. Aviles RJ, Askari AT, Lindahl B, Wallentin L, Jia G, Ohman EM, Mahaffey KW, et al. Troponin T levels in patients with acute coronary syndromes, with or without renal dysfunction. N Engl J Med. 2002;346(26):20472052.

29. Lindahl B, Toss H, Siegbahn A, Venge P, Wallentin L. Markers of myocardial damage and inflammation in relation to long-term mortality in unstable coronary artery disease. FRISC Study Group. Fragmin during Instability in Coronary Artery Disease. N Engl J Med. 2000;343(16):1139-1147.

30. Latini R, Masson S, Anand IS, Missov E, Carlson M, Vago T, Angelici L, et al. Prognostic value of very low plasma concentrations of troponin $\mathrm{T}$ in patients with stable chronic heart failure. Circulation. 2007;116(11):1242-1249.

31. Setsuta K, Seino Y, Takahashi N, Ogawa T, Sasaki K, Harada A, Takano T, et al. Clinical significance of elevated levels of cardiac troponin $\mathrm{T}$ in patients with chronic heart failure. Am J Cardiol. 1999;84(5):608611, A609.

32. Ishii J, Cui W, Kitagawa F, Kuno T, Nakamura Y, Naruse $\mathrm{H}$, Mori Y, et al. Prognostic value of combination of cardiac troponin $\mathrm{T}$ and B-type natriuretic peptide after initiation of treatment in patients with chronic heart failure. Clin Chem. 2003;49(12):2020-2026.

33. Del Carlo CH, Pereira-Barretto AC, Cassaro-Strunz C, Latorre Mdo R, Ramires JA. Serial measure of cardiac troponin $\mathrm{T}$ levels for prediction of clinical events in decompensated heart failure. J Card Fail. 2004;10(1):4348.

34. Wang Z, Inami S, Kirinoki S, Yamamoto H, Takagi G, Aoki S, Kato K, et al. Angioscopic study of silent plaque disruption in nonischemic related coronary artery in patients with stable ischemic heart disease. Int Heart J. 2010;51(6):383-387.

35. Kappelle PJ, van Tol A, Wolffenbuttel BH, Dullaart RP. Cholesteryl ester transfer protein inhibition in cardio- 
vascular risk management: ongoing trials will end the confusion. Cardiovasc Ther. 2011;29(6):e89-99.

36. Davignon J. Pleiotropic effects of pitavastatin. Br J Clin Pharmacol. 2012;73(4):518-535.

37. Teramoto T, Sasaki J, Ueshima H, Egusa G, Kinoshita
M, Shimamoto K, Daida H, et al. Executive summary of Japan Atherosclerosis Society (JAS) guideline for diagnosis and prevention of atherosclerotic cardiovascular diseases for Japanese. J Atheroscler Thromb. 2007;14(2):45-50. 